\title{
A study of management and outcome of tumors of ovary among women of reproductive age group
}

\section{Priyadarshika M.*}

\begin{abstract}
Department of Obstetrics and Gynecology, Malla Reddy Medical College for Women, Suraram, Hyderabad,
\end{abstract} Telangana, India

Received: 22 February 2018

Accepted: 28 March 2018

\author{
*Correspondence: \\ Dr. Priyadarshika M., \\ E-mail: dr_priyadarshika@yahoo.com
}

Copyright: (c) the author(s), publisher and licensee Medip Academy. This is an open-access article distributed under the terms of the Creative Commons Attribution Non-Commercial License, which permits unrestricted non-commercial use, distribution, and reproduction in any medium, provided the original work is properly cited.

\begin{abstract}
Background: Variety of presentations of each and every type of the tumor of the ovaries and their asymptomatic nature in the initial stages of the cancer brings out the disease in very late stages. In the late stages of the malignancy of the ovaries, even chemotherapy or even surgical management is of limited use. Objective of this study was to study of management and outcome of tumors of ovary among women of reproductive age group

Methods: Present study was follow-up study. Patients were followed from diagnosis to surgery till the six months post-surgery. A total of 56 eligible study subjects with any kind of tumor of ovary posted for surgery in the department of Obstetrics and Gynecology were included in the present study and studied in the present study which lasted for two years.

Results: Maximum (64.3\%) were managed by oophorectomy. $87.5 \%$ of tumors were benign and $10.7 \%$ were malignant. Maximum cases were of serous cystadenoma in $44.9 \%$ of the cases among benign tumors. Out of 22 cases of serous cystadenoma, maximum i.e. 16 underwent oophorectomy. One case of Dysgerminoma affecting one ovary was in stage Ia but not having metastatic nodules or ascites. Papillary mucinous cystadeno carcinoma in stage IIIc received Salvage CT with multi drug regimen with 3 Number of cycles of chemotherapy. Three cases died and one lost to follow up.

Conclusions: Benign tumors of the ovary were the most common among women. Each case was unique histopathlogically and stage wise. This feature of tumors of the ovaries makes it difficult to diagnose easily and make management more difficult. Hence thorough study of each case is required to understand them properly.
\end{abstract}

Keywords: Benign tumor of the ovary, Cystadenoma, Oophorectomy

\section{INTRODUCTION}

Tumors of ovary which are malignant in nature are one of the leading causes of mortality in many parts of the world. In Ghana, it stands in the fifth position among the causes of mortality. Generally, on an average, tumor of the ovary is found in the fourth decade of the life of women. And this is due to the fact that most of the patients are diagnosed in late stages of cancer of the ovary. Hence maximum mortality among women due to the ovary cancer is seen mostly in the third decade. ${ }^{1}$ From the age of 30 years and onwards among women the ovarian cancer incidence increases, and the incidence is seen highest in the age group of 70 years among women. The type of tumor of the ovaries differs in different age groups among women. The type of tumor is also found to be specific for specific race types and different regions of the world. ${ }^{2}$

Progeny production takes place in the ovary. Sex cells are present in the ovaries. Ovaries also contain "mesenchymal cells which are totipotential and 
multipotential respectively." Hence due to this peculiarity, any kind of malignant tumor can occur from ovaries. $^{3}$

For gynecologist malignant and non-malignant tumors of the ovary are a challenge. Some types of non-malignant tumors of the ovaries present as mass in the pelvis and for Gyneconcologists it resembles like a malignant tumor of the ovary. Hence it is very important that the tumor must be appropriately identified and classified. ${ }^{4}$

Malignant tumor of the ovaries is complicated subject matter in the oncology history. This is because of the variety of histology types and presentation of each and every tumor of the ovary. ${ }^{5}$

Cancer of the ovaries is the seventh leading cause of mortality due to malignancy globally among females. The cancer of the ovaries constitutes a total of $8.7 \%$ of all cancers in India from various parts of the country. ${ }^{6}$

Variety of presentations of each and every type of the tumor of the ovaries and their asymptomatic nature in the initial stages of the cancer brings out the disease in very late stages. In the late stages of the malignancy of the ovaries, even chemotherapy or even surgical management is of limited use. ${ }^{7}$

Up to one third of tumors of ovaries among the postmenopausal females are found to be malignant in nature. Epithelial malignant tumors of ovary are usually seen in the fifth decade of life of females. Compared to postmenopausal females, only $7 \%$ of the tumors of the ovaries are malignant among the women of premenopausal age group. Prognosis is better if diagnosed in early age group. ${ }^{8}$

With this background present study was carried out to study the management and outcome of tumors of ovary among women of reproductive age group.

\section{METHODS}

Present study was follow-up study. Patients were followed from diagnosis to surgery till the six months post-surgery. A total of 56 eligible study subjects with any kind of tumor of ovary posted for surgery in the department of Obstetrics and Gynecology were included in the present study and studied in the present study which lasted for two years.

Study protocol was submitted to the Institutional Ethics Committee and after receiving the approval from them, study was started. Individual patient informed consent was obtained. Females with confirmed diagnosis of ovarian tumor either benign or malignant in nature and those females giving consent for the present study were included in the present study. Females, with confirmed ovarian tumor but not willing to participate in the present study, and those females; who had associated complications or seriously ill were excluded from the present study.

All those who required surgery were posted. Thorough history and detailed clinical examination was carried out for each and every included case. Complete surgical profile including chest X ray and ECG was done to verify the fitness for the study in the present study. Afterwards, anesthetic opinion was taken. After certificate of fitness from anaesthetist, the women were posted for surgery. Depending upon the requirement different surgical approaches were planned for different types of cases with tumor of the ovaries. Some underwent cystectomy. Oophorectomy was done in maximum number of cases. In some cases, combined oophorectomy plus cystectomy was done. While in some cases TAH plus BSO method was applied. One case underwent vaginal hysterectomy plus oophorectomy. Two cases required debulking.

After surgery the specimen were properly preserved and sent for histopathology. Histopathology reports were collected and analyzed in the present study. Tumors were first classified as benign, malignant or potential of malignancy. Staging of tumors was observed based on histopathology reports. Intra operatively the type of tumor and affected parts with presence of metastatic nodules or ascites or both and also the staging was noted and recorded for the present study.

Post operatively some patients were given chemotherapy. Number of drugs they received and the cycles completed by them was noted and recorded for the present study. All patients were followed for outcome. The data was recorded and analyzed using proportions

\section{RESULTS}

Table 1 shows surgical management of ovarian tumors. Maximum (64.3\%) were managed by oophorectomy. Cystectomy was done in $19.6 \%$ of the cases. Oophorectomy + cystectomy was done in $1.8 \%$ of the cases. TAH + BSO were done in $8.9 \%$ of the cases. Vaginal hysterectomy + oophorectomy were done in $1.8 \%$ of the cases. Debulking was done in $3.6 \%$ of the cases.

Table 1: Surgical management of ovarian tumors.

\begin{tabular}{|lll|}
\hline Type of surgery & No. & $\%$ \\
\hline Cystectomy & 11 & 19.6 \\
\hline Oophorectomy & 36 & 64.3 \\
\hline Oophorectomy + cystectomy & 1 & 1.8 \\
\hline TAH + BSO & 5 & 8.9 \\
\hline Vaginal hysterectomy + oophorectomy & 1 & 1.8 \\
\hline Debulking & 2 & 3.6 \\
\hline
\end{tabular}

Table 2 shows distribution as per type of tumor. Maximum tumors of the ovary were benign in nature in $87.5 \%$ of the cases. Malignant tumors of the ovary were 
found in $10.7 \%$ of the cases and there was one case of tumor which was of low malignant potential.

Table 2: Distribution as per type of tumor.

\begin{tabular}{|lll|}
\hline Type of tumor & Number & Percentage \\
\hline Benign & 49 & 87.5 \\
\hline Low malignant potential & 1 & 1.8 \\
\hline Malignant & 6 & 10.7 \\
\hline
\end{tabular}

Table 3 shows histopathology of benign tumors of ovary. Maximum cases were of serous cystadenoma in $44.9 \%$ of the cases. Dermoid cyst was seen in $34.7 \%$ of the cases. Mucinous cystademona was seen $18.4 \%$ of the cases. Sclerosing stromal tumor was seen in only one case.

Table 3: Histopathology of benign tumors of ovary ( $N=49)$.

\begin{tabular}{|lll|}
\hline Type of tumor & Number & Percentage \\
\hline Serous cystadenoma & 22 & 44.9 \\
\hline Mucinous cystadenoma & 9 & 18.4 \\
\hline Dermoid cyst & 17 & 34.7 \\
\hline Sclerosing stromal tumor & 1 & 2 \\
\hline
\end{tabular}

Table 4 shows stage and histopathology of malignant tumors of ovary. Dysgerminoma was present in two cases and both the cases were in Ia stage. Yolk sac tumor was present in one case with III c stage. Mucinous cystadeno carcinoma was present in two cases with one case having stage III c and another with stage Ia. Papillary serous cystadeno carcinoma was present in one case with $\mathrm{Ib}$ stage. Mucinous tumor of low malignant potential was present in one case and could not be stages.

Table 4: Stage and histopathology of malignant tumors of ovary $(\mathrm{N}=7)$.

\begin{tabular}{|llll|}
\hline Type of tumor & No. & $\%$ & Stage \\
\hline Dysgerminoma & 2 & 28.57 & Ia \\
\hline Yolk sac tumor & 1 & 14.29 & IIIc \\
\hline $\begin{array}{l}\text { Mucinous cystadeno } \\
\text { carcinoma }\end{array}$ & 2 & 28.57 & $\begin{array}{l}\text { Ia and } \\
\text { IIIc }\end{array}$ \\
\hline $\begin{array}{l}\text { Papillary serous cystadeno } \\
\text { carcinoma }\end{array}$ & 1 & 14.29 & Ib \\
\hline $\begin{array}{l}\text { Mucinous tumor of low } \\
\text { malignant potential }\end{array}$ & 1 & 14.29 & \\
\hline
\end{tabular}

Table 5 shows management of benign tumors of ovary. Out of 22 cases of serous cystadenoma, maximum i.e. 16 underwent oophorectomy. Out of 9 cases of Mucinous cystadenoma, maximum i.e. five also underwent oophorectomy. Out of 17 cases of dermoid cyst, maximum i.e. 12 also underwent oophorectomy. There was only one case of Sclerosing stromal tumor which was also managed by oophorectomy.

Table 6 shows management of malignant tumors of ovary. Out of 2 cases of serous cystadenoma, both underwent oophorectomy. Out of 2 cases of Mucinous cystadenoma, 1 underwent oophorectomy. There was only one case of serous cystadeno carcinoma which was managed by $\mathrm{TAH}+\mathrm{BSO}$.

Table 5: Management of benign tumors of ovary.

\begin{tabular}{|c|c|c|c|c|c|}
\hline Type & Cystectomy & Oophorectomy & $\begin{array}{l}\text { Cystectomy + } \\
\text { Oophorectomy }\end{array}$ & $\mathrm{TAH}+\mathrm{BSO}$ & $\begin{array}{l}\text { Vaginal hysterectomy + } \\
\text { Oophorectomy }\end{array}$ \\
\hline $\begin{array}{l}\text { Serous } \\
\text { cystadenoma }\end{array}$ & 3 & 16 & - & 3 & - \\
\hline $\begin{array}{l}\text { Mucinous } \\
\text { cystadenoma }\end{array}$ & 3 & 5 & - & - & 1 \\
\hline Dermoid cyst & 4 & 12 & 1 & - & - \\
\hline $\begin{array}{l}\text { Sclerosing } \\
\text { stromal tumor }\end{array}$ & - & 1 & - & - & - \\
\hline
\end{tabular}

Table 6: Management of malignant tumors of ovary.

\begin{tabular}{lllll} 
Type & Cystectomy & Oophorectomy & TAH + BSO & Debulking \\
Dysgerminoma & - & 2 & - & - \\
\hline Mucinous cystadeno carcinoma & - & - & 1 & 1 \\
\hline Serous cystadeno carcinoma & - & - & 1 & - \\
LMP Mucinous tumor & 1 & - & - & - \\
\hline
\end{tabular}

Table 7 shows intra operative findings in malignant tumors. One case of Dysgerminoma affecting one ovary was in stage Ia but not having metastatic nodules or ascites. One case of Dysgerminoma affecting one ovary was in stage Ia not having metastatic nodules but was associated with ascites. One case of Yolk sac tumor 
affecting Ovaries, bowel, omentum, and peritoneum was in stage IIIc and having metastatic nodules and ascites. Mucinous cystadenoma carcinoma in stage IIIc and having metastatic nodules and ascites. One case of Mucinous cystadenoma carcinoma in stage IIIc not having metastatic nodules but was associated with ascites. Serous cystadenoma carcinoma in stage $\mathrm{I}$ b affecting both the ovaries but not having metastatic nodules or ascites. One case of Low malignant potential mucinous tumor affecting one ovary was in stage Ia but not having metastatic nodules or ascites.

Table 7: Intra operative findings in malignant tumors.

\begin{tabular}{|c|c|c|c|c|}
\hline Type & Tumor involving & $\begin{array}{l}\text { Metastatic } \\
\text { nodules }\end{array}$ & Ascites & Stage \\
\hline Dysgerminoma & One ovary & - & - & Ia \\
\hline Dysgerminoma & One ovary & - & + & Ia \\
\hline Yolk sac tumor & Ovaries, bowel, omentum, peritoneum & + & + & IIIc \\
\hline Mucinous cystadenoma carcinoma & Ovaries, uterus, intestines, omentum & + & + & IIIc \\
\hline Mucinous cystadenoma carcinoma & One ovary & - & + & Ia \\
\hline Serous cystadenoma carcinoma & Both ovaries & - & - & $\mathrm{Ib}$ \\
\hline $\begin{array}{l}\text { Low malignant potential mucinous } \\
\text { tumor }\end{array}$ & One ovary & - & - & Ia \\
\hline
\end{tabular}

Table 8: Distribution of study subjects as per chemotherapy.

\begin{tabular}{|llll|} 
Type of tumor & Stage & $\begin{array}{l}\text { No. of cycles of } \\
\text { chemotherapy }\end{array}$ & No. of drugs \\
\hline Dysgerminoma & Ia & 3 & 2 drugs \\
\hline Papillary mucinous cystadeno carcinoma & IIIc & 3 & Salvage CT with multi drug regimen \\
\hline Papillary serous cystadeno carcinoma & Ib & 5 & 2 drugs \\
\hline
\end{tabular}

Table 8 shows distribution of study subjects as per chemotherapy. Dysgerminoma cases in stage Ia received chemotherapy with two drugs with 3 Number of cycles of chemotherapy. Papillary mucinous cystadeno carcinoma in stage IIIc received Salvage CT with multi drug regimen with 3 Number of cycles of chemotherapy. Papillary serous cystadeno carcinoma in stage Ib received chemotherapy with two drugs with 3 Number of cycles of chemotherapy.

Table 9: Out come at follow up of patients with malignant ovarian tumor.

\begin{tabular}{ll|} 
Status & Number of patients \\
\hline Asymptomatic & 2 \\
\hline Receiving chemotherapy & 1 \\
\hline Dead & 3 \\
\hline Lost to follow up & 1 \\
\hline
\end{tabular}

Table 9 shows outcome at follow up of patients with malignant ovarian tumor. 2 cases were asymptomatic. One was still receiving chemotherapy. Three died and one lost to follow up.

\section{DISCUSSION}

Maximum (64.3\%) were managed by oophorectomy. Cystectomy was done in $19.6 \%$ of the cases.
Oophorectomy + cystectomy were done in $1.8 \%$ of the cases. TAH + BSO were done in $8.9 \%$ of the cases. Vaginal hysterectomy + oophorectomy were done in $1.8 \%$ of the cases. Debulking was done in $3.6 \%$ of the cases. Maximum tumors of the ovary were benign in nature in $87.5 \%$ of the cases. Malignant tumors of the ovary were found in $10.7 \%$ of the cases and there was one case of tumor which was of low malignant potential. Maximum cases were of serous cystadenoma in $44.9 \%$ of the cases. Dermoid cyst was seen in $34.7 \%$ of the cases. Mucinous cystademona was seen $18.4 \%$ of the cases. Sclerosing stromal tumor was seen in only one case. Dysgerminoma was present in two cases and both the cases were in Ia stage. Yolk sac tumor was present in one case with III c stage. Mucinous cystadeno carcinoma was present in two cases with one case having stage III $\mathrm{c}$ and another with stage Ia. Papillary serous cystadeno carcinoma was present in one case with Ib stage. Mucinous tumor of low malignant potential was present in one case and could not be stages.

Out of 22 cases of serous cystadenoma, maximum i.e. 16 underwent oophorectomy. Out of 9 cases of Mucinous cystadenoma, maximum i.e. five also underwent oophorectomy. Out of 17 cases of dermoid cyst, maximum i.e. 12 also underwent oophorectomy. There was only one case of Sclerosing stromal tumor which was also managed by oophorectomy. Out of 2 cases of serous cystadenoma, both underwent oophorectomy. Out of 2 
cases of Mucinous cystadenoma, 1 underwent oophorectomy. There was only one case of serous cystadeno carcinoma which was managed by $\mathrm{TAH}+$ BSO. One case of Dysgerminoma affecting one ovary was in stage Ia but not having metastatic nodules or ascites. One case of Dysgerminoma affecting one ovary was in stage Ia not having metastatic nodules but was associated with ascites. One case of Yolk sac tumor affecting ovaries, bowel, omentum, and peritoneum was in stage IIIc and having metastatic nodules and ascites. Mucinous cystadenoma carcinoma in stage IIIc and having metastatic nodules and ascites. One case of Mucinous cystadenoma carcinoma in stage IIIc not having metastatic nodules but was associated with ascites. Serous cystadenoma carcinoma in stage I b affecting both the ovaries but not having metastatic nodules or ascites.

One case of low malignant potential mucinous tumor affecting one ovary was in stage Ia but not having metastatic nodules or ascites. Dysgerminoma cases in stage Ia received chemotherapy with two drugs with 3 Number of cycles of chemotherapy. Papillary mucinous cystadeno carcinoma in stage IIIc received Salvage CT with multi drug regimen with 3 Number of cycles of chemotherapy. Papillary serous cystadeno carcinoma in stage $\mathrm{Ib}$ received chemotherapy with two drugs with 3 Number of cycles of chemotherapy. 2 cases were asymptomatic. One was still receiving chemotherapy. Three died and one lost to follow up.

Onyiaorah IV et al studied results of biopsy of ovaries in more than 450 cases. They found that $80.3 \%$ were benign tumors and $19.7 \%$ were malignant tumors. ${ }^{9}$ In the present study we also found that maximum were benign tumors and few were malignant tumors. More than half were germ cell tumors. One fourth was tumors from surface epithelium. $15 \%$ were tumors of sex cord stroma. The most common benign tumor was mature teratoma. It occurred commonly in the age group of 20-29 years. The most common malignant tumor was serous cystadenocarcinoma. It occurred commonly in the age group of 30-39 years.

Mohammed A et al observed that the incidence of ovarian tumors was $8.6 \%$ among the pediatric girls. $32 \%$ of the malignant tumors were seen in this age group. In $31.2 \%$ of the cases Burkitt's lymphoma was seen. $58 \%$ was germ cell tumors. $2.1 \%$ was the epithelial tumors. ${ }^{10}$

Junaid TA analyzed the cases in under 20 years of age group. Burkitt's lymphoma was the most commonly seen tumor. In all cases it was bilateral. $67.1 \%$ were the germ cell tumors. ${ }^{11}$

Pilli GS et al also found that majority presented with benign and few had malignant tumors which is similar to the finding of the present study. ${ }^{12}$ The most common variety was epithelial tumors. In one fifth cases it was the germ cell tumors. The author reported that the ovarian tumors incidence was found from as early as 8 months of age to as high as 74 years of age. But the most commonly affected age group was 21-40 years of age.

Clement PB et al described atypical presentation of ovarian tumors in four cases. ${ }^{13}$ Two cases presented with leiomyomas, one case as endometrial adenocarcinoma and one case presented as a very large mass in the abdomen.

Al-Fozan $\mathrm{H}$ et al found that tumor being on left was 3.3 times more likely to occur than on the right side. ${ }^{14}$ But adhesions were 2.6 times more common on right side than on the left side. Endometrioma was 2.3 times more on the left side than on the right side.

Martinez-Onsurbe $\mathrm{P}$ et al noted that aspiration technique to diagnose tumors was having less sensitivity. ${ }^{15}$ The author cautioned that malignant tumors may be under diagnosed as the samples obtained by this technique are inadequate.

Kreuzer GF et al found that it is difficult to diagnose and differentiate between malignant and non-malignant tumors of the ovary using only one or two parameters. ${ }^{16}$ But use of three parameters in combination can lead to near to accuracy diagnosis. They concluded from their study that if three parameters are indicating towards a malignant tumor of the ovary then the surgical management should be considered.

\section{CONCLUSION}

Benign tumors of the ovary were the most common among women. Each case was unique histopathlogically and stage wise. This feature of tumors of the ovaries makes it difficult to diagnose easily and make management more difficult. Hence thorough study of each case is required to understand them properly.

\section{Funding: No funding sources}

Conflict of interest: None declared

Ethical approval: The study was approved by the Institutional Ethics Committee

\section{REFERENCES}

1. Wiredu EK, Armah BH. Cancer mortality patterns in Ghana: a 10-year review of autopsies and hospital mortality. BMC Public Health. 2006;6:159.

2. Moorman PG, Palmieri RT, Akushevich L, Berchuck A, Schildkraut JM. Ovarian Cancer Risk Factors in African-American and White Women. Am J Epidemiol. 2009;170(5):598-606.

3. Sikdar K, Kumar P, Roychowdhary NN. A study of ovarian malignancy: A review of 149 cases. J Obstet Gynaecol India. 1981;30:478-80.

4. Gupta N, Bisht D, Agarwal AK, Sharma VK. Retrospective and prospective study of ovarian 
tumors and tumour-like lesions. Indian $\mathrm{J}$ Pathol Microbiol. 2007;50(3):525-7.

5. Misra RK, Sharma SP, Gupta U, Gaur R, Mishra SD. Pattern of ovarian neoplasm in eastern UP. J Obstet Gynecol India. 1991;30:242-6.

6. Mondal SK, Banyopadhyay R, Nag DR, Roychowdhury S, Mondal PK, Sinha SK. Histologic pattern, bilaterality and clinical evaluation of 957 ovarian neoplasms: A 10-year study in a tertiary hospital of eastern India. $\mathbf{J}$ Can Res Ther. 2011;7:433-7.

7. Saxena HMK, Devi G, Prakash P, Pankajam P. Ovarian neoplasms: a retrospective study of 356 cases. J Obstet Gynecol India. 1980;20(6):523-7.

8. Berek JS, Berek NS. Novak's gynecology. In: Ovarian and fallopian tube cancer, eds. Berek JS. $14^{\text {th }}$ ed. New Delhi: Wolters Kluwer health (India) private limited; 2014;1457-1547.

9. Onyiaorah IV, Anuobi CC, Banoj AA, Fatima AA, Nwankwo KC. Histopathological patterns of ovarian tumors seen in Lagos University Teaching Hospital: a ten-year retrospective study. Nig Q J Hosp Med. 2011;21(2):114-8.

10. Mohammed A, Malami SA, Calvin B, Abdullahi K. A histopathological study of ovarian neoplasms in children in a tertiary hospital of northern Nigeria. Afr J Pediatr Surg. 2010;7(2):75-7.
11. Junaid TA. Ovarian neoplasms in children and adolescents in Ibadan, Nigeria. Cancer. 1981;47(3):610-4.

12. Pilli GS, Suneeta KP, Dhaded AV, Yenni VV. Ovarian tumors: a study of 282 cases. J Indian Med Assoc. 2002;100(7):420-7.

13. Clement PB, Young RH, Scully RE. Necrotic pseudoxanthomatous nodules of ovary and peritoneum in endometriosis. Am J Surg Pathol. 1988;12(5):390-7.

14. Al-Fozan H, Tulandi T. Left lateral predisposition of endometriosis and endometrioma. Obstet Gynecol. 2003;101(1):164-6.

15. Martinez-Onsurbe P, Villaespesa RA, Anquela SJM, Ruiz VPL. Aspiration cytology of 147 adnexal cysts with histologic correlation. Acta Cytol. 2001;45(6):941-7.

16. Kreuzer GF, Paradowski T, Wurche KD, Flenker H. Neoplastic or non-neoplastic ovarian cyst? The role of cytology. Acta Cytol. 1995;39(5):882-6.

Cite this article as: Priyadarshika M. A study of management and outcome of tumors of ovary among women of reproductive age group. Int J Reprod Contracept Obstet Gynecol 2018;7:1918-23. 